\title{
Systolic aortic regurgitation predicts all-cause mortality and hospitalization in outpatients with heart failure and preserved ejection fraction
}

\author{
(1) Ismail Bolat, ${ }^{1}$ (1) Murat Biteker ${ }^{2}$ \\ ${ }^{1}$ Department of Cardiology, Fethiye State Hospital, Mugla, Turkey \\ ${ }^{2}$ Department of Cardiology, Mugla Sitki Kocman University Faculty of Medicine, Mugla, Turkey
}

\begin{abstract}
OBJECTIVE: Systolic aortic regurgitation (SAR) is considered to be a specific sign of heart failure (HF). However, the prevalence and importance of SAR in patients with HF and preserved ejection fraction (HFpEF) are unknown. Therefore, we sought to examine the prevalence of SAR in HFpEF outpatients and its association with all-cause mortality and/or cardiovascular hospitalizations during a 1-year follow-up.
\end{abstract}

METHODS: We enrolled 301 consecutive outpatients with HFpEF (mean age of $67.3 \pm 9.6$ years, $53.5 \%$ women) and prospectively followed up for one year. Demographic, clinical, echocardiographic, and laboratory data were obtained at study entry. The composite endpoint of this study was all-cause mortality or HF-related hospitalizations in one year.

RESULTS: SAR was noted in $30(9.9 \%)$ of the patients, and 38 patients $(12.6 \%)$ reached the primary endpoint. The primary composite endpoint in one year was higher for the patients with SAR $(26.3 \%)$ compared to the patients without SAR $(7.6 \%$, $\mathrm{p}<0.001)$. After adjusting for important covariates, SAR remained independently associated with primary outcome (OR 2.315; 95\% CI 1.188-5.477; $p=0.008$ ).

CONCLUSION: To our knowledge, this is the first study to demonstrate that the presence of SAR is associated with adverse events in patients with HFpEF.

Keywords: Echocardiography; heart failure and preserved ejection fraction; outcome; prognosis; systolic aortic regurgitation.

Cite this article as: Bolat I, Biteker M. Systolic aortic regurgitation predicts all-cause mortality and hospitalization in outpatients with heart failure and preserved ejection fraction. North Clin Istanb 2020;7(4):335-340.

Weart failure with preserved ejection fraction $1(\mathrm{HFpEF})$ is the most frequent form of heart failure (HF) in ambulatory patients, and therefore, early identification of high-risk patients for hospitalization and/or death is crucial $[1,2]$. Improvements in risk stratification by identification of new risk scores, biomarkers and imaging techniques have been extensively investigated in the past decade [3-5]. Several echocardiographic parameters, such as left ventricular hypertrophy, pulmonary hypertension, and various indices of diastolic stiffness, have also been associated with worse prognosis in HFpEF [6-8].

Aortic regurgitation usually occurs in diastole, but systolic aortic regurgitation (SAR) is caused by the inability of ventricular contraction to overcome the aortic pressure in systole [9]. SAR is usually associated with premature ventricular contractions or atrial fibrillation [10]. In a small study, SAR was detected in $2.3 \%$ of patients admitted to the hospital and was more frequent in patients with HF [11]. Although there is growing

Received: July 10, 2019 Accepted: January 15, 2020 Online: Februay 11, 2020

Correspondence: Ismail BOLAT, MD. Fethiye Devlet Hastanesi, Kardiyoloji Klinigi, Mugla, Turkey.

Tel: +90 5072450146 e-mail: drismail_bolat@hotmail.com

(c) Copyright 2020 by Istanbul Provincial Directorate of Health - Available online at www.northclinist.com 
evidence that SAR is not an exceptional phenomenon, the prevalence and prognostic significance of SAR in patients with HF remains unknown. Therefore, is the present study aims to examine the prevalence and significance of SAR in predicting all-cause mortality or HFrelated hospitalizations in patients with $\mathrm{HFpEF}$.

\section{MATERIALS AND METHODS}

\section{Patients}

After Ethics Committee approval (MUSKU, 16.08.2016, $14 / 2$ ), this prospective study was conducted in our hospital between March 2017 and May 2018. The study group included all consecutive adult outpatients diagnosed with HFPEF. Patients were defined as HFpEF according to current guidelines [12]. Patients were excluded from this study if they need hospitalization during the index admission. Patients with severe valvular heart diseases, severe chronic pulmonary disease; hypertrophic cardiomyopathy; and pregnant patients were excluded from this study.

\section{Measurements, Data collection and Endpoints}

For each patient, data for comorbid conditions, patients' demographic characteristics, medications, and echocardiographic parameters were recorded at admission to the outpatient cardiology clinic. Data were collected by telephone interviews and outpatient clinic visits.

All of the consecutive outpatients with HFpEF underwent comprehensive transthoracic echocardiography [13]. Systolic aortic regurgitation is explained as the inability of the ventricular beat to overcome the aortic pressure associated with some degree of valvular incompetence. Therefore, the SAR was defined as the presence of blood flow from the aorta to the left ventricular outflow tract during systole (Fig. 1). The presence/absence of SAR was recorded. Routine laboratory variables and NT-proBNP levels were measured at admission to the outpatient.

All patients were prospectively followed up for 12 months or until death. The written informed consent was obtained from all patients. The primary composite endpoint was all-cause death and hospitalization for $\mathrm{HF}$ at 12 months.

\section{Statistical Analysis}

In the evaluation of the differences between the categorical variables, Fisher's exact test was used in a row, and

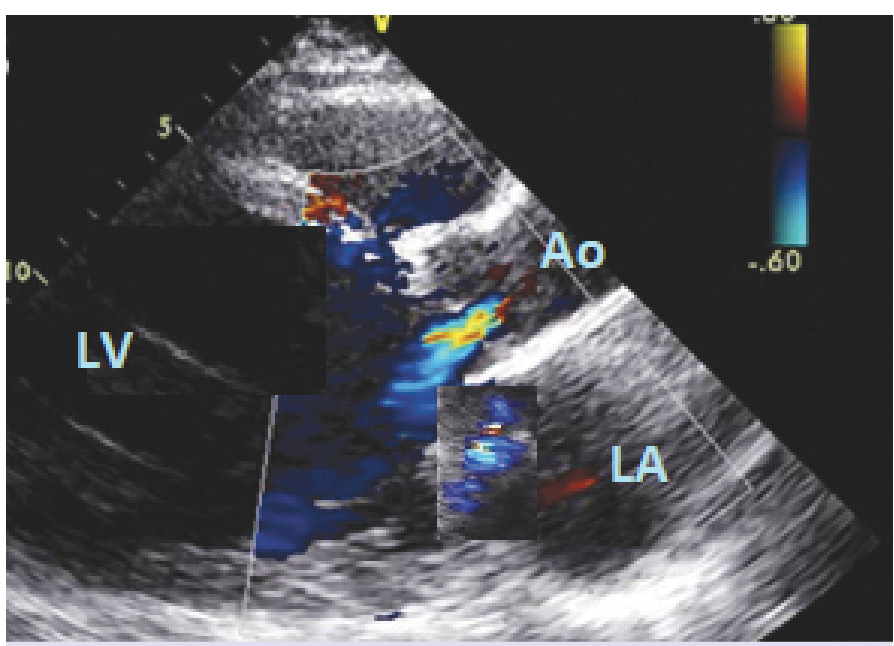

FIGURE 1. Color Doppler echocardiography showing simultaneous aortic and mitral regurgitation flows during the systole.

LV: Left ventricle; LA: Left atrium; Ao: Aorta.

column tables and Pearson Chi-Square Test was used for $2 \times 2$ tables. To compare continuous variables groups, independent $t$-tests and Mann-Whitney $U$ tests were used. Univariate and multivariable logistic regression analyses were performed to determine independent predictors of outcomes. For statistical analysis, the Jamovi (Jamovi Project 2018, version 0.9.1.7, retrieved from https:// www.jamovi.org) (open source) program was used.

\section{RESULTS}

A total of 301 consecutive ambulatory HFpEF patients, aged 18 years or older (mean age of $67.3 \pm 9.6$ years, $53.5 \%$ of women) were included in this study.

\section{Comparison of the Patients with and without SAR}

SAR was noted in $30(9.9 \%)$ patients. The patients with SAR were older, were more likely be symptomatic (higher NYHA functional class, more frequent crepitant rales, and orthopnea), were more likely to have chronic lung diseases, and atrial fibrillation compared to without SAR (Table 1). Patients with SAR had higher NT-proBNP levels and were more likely to have mitral regurgitation (moderate or higher) on admission.

Comparison of the Patients who Reached and who did not Reach Primary Outcome

Thirty-eight patients $(12.6 \%)$ reached the composite endpoints in one year. The comparison of the patients who reached and who did not reach primary outcome 
TABLE 1. Characteristics of the patients according to the presence of systolic aortic regurgitation

\begin{tabular}{|c|c|c|c|}
\hline & Without SAR $(n=271)$ & With SAR $(n=30)$ & $\mathrm{p}$ \\
\hline Gender (female) \% & 53.5 & 53.3 & 0.354 \\
\hline Age, years & 65 & 69 & $<0.001$ \\
\hline Body mass index, $\mathrm{kg} / \mathrm{m}^{2}$ & 28 & 28 & 0.086 \\
\hline Smoking \% & 20.3 & 19.1 & 0.213 \\
\hline NYHA III/IV symptoms \% & 22.5 & 53.3 & $<0.001$ \\
\hline Pulmonary crepitations \% & 19.1 & 30.0 & 0.004 \\
\hline \multicolumn{4}{|l|}{ Comorbidities } \\
\hline Hypertension \% & 72.3 & 73.3 & 0.355 \\
\hline Diabetes mellitus \% & 25.1 & 26.7 & 0.425 \\
\hline Chronic kidney disease \% & 8.1 & 6.7 & 0.462 \\
\hline Atrial fibrillation \% & 26.6 & 53.3 & $<0.001$ \\
\hline \multicolumn{4}{|l|}{ Laboratory data } \\
\hline NT-proBNP, pg/ml & 301.8 & 535 & $<0.001$ \\
\hline Fasting blood glucose, mg/dl & 98 & 99 & 0.138 \\
\hline Serum creatinine, mg/dl & 0.80 & 0.81 & 0.525 \\
\hline Hemoglobin, g/dl & 12.7 & 12.9 & 0.674 \\
\hline \multicolumn{4}{|l|}{ Echocardiography } \\
\hline LVEF, \% & 59 & 58 & 0.680 \\
\hline IVS dimension, mm & 1223.4 & 11 & 0.451 \\
\hline$\geq$ Moderate mitral regurgitation $\%$ & 27 & 33.3 & 0.044 \\
\hline
\end{tabular}

Data were presented as median or number (\%). SAR: Systolic aortic regurgitation; NYHA: New York Heart Association; NT-proBNP: N-terminal pro B-type natriuretic peptide; LVEF: Left ventricle ejection fraction; IVS: Interventricular septum.

is presented in Table 2. However, patients who died or who were hospitalized for HF during the study period were older, had more frequently atrial fibrillation, and chronic obstructive pulmonary disease compared to the patients without adverse events. Patients who had experienced primary outcome were also more likely to be symptomatic, were more likely to have mitral regurgitation and had higher NT-proBNP levels on admission. The primary composite endpoint in one year was higher for patients with SAR $(26.3 \%)$ compared to the patients without $\operatorname{SAR}(7.6 \%, \mathrm{p}<0.001)$.

\section{Predictors of all-cause Mortality}

All-cause mortality during follow-up was 3.9\% (11 patients). Multivariate analysis showed that age (OR:2.678; 95\% CI: 1.567-7.219; $\mathrm{p}=0.013)$, NT-proBNP $>459$
pg/mL (OR: 2.671; 95\% CI: 1.435-7.451; p<0.001), and presence of SAR (OR: 2.673; 95\% CI 1.295-5.709; $\mathrm{p}=0.001)$ predicted mortality.

\section{Predictors of Hospitalization for Heart Failure}

Thirty-two patients $(10.6 \%)$ required at least one hospitalization due to a HF during follow-up. Multivariate analysis showed that age (OR: 2.109; 95\% CI: $1.407-$ 5.543; $\mathrm{p}=0.024)$, presence of orthopnea on admission (OR: 1.491; 95\% CI: 1.019-3.214; $\mathrm{p}=0.039$ ), and NTproBNP > $411 \mathrm{pg} / \mathrm{mL}$ (OR: 2.171; 95\% CI: 1.4094.341; $\mathrm{p}=0.043)$ predicted hospitalization due to $\mathrm{HF}$.

\section{Predictors of Composite Endpoint}

The incidence of death or hospitalization for HF in one 
TABLE 2. Comparison of the patients who reached and did not reach the primary outcome

\begin{tabular}{|c|c|c|c|}
\hline & Without events $(n=263)$ & With events $(n=38)$ & $\mathrm{p}$ \\
\hline Gender (female) \% & 53.6 & 52.6 & 0.323 \\
\hline Age, years & 63 & 68 & 0.001 \\
\hline Body mass index, $\mathrm{kg} / \mathrm{m}^{2}$ & 27 & 28 & 0.136 \\
\hline Smoking \% & 19.8 & 28.9 & 0.081 \\
\hline NYHA III/IV symptoms \% & 23.9 & 36.8 & 0.065 \\
\hline Orthopnea \% & 22.4 & 42.1 & 0.001 \\
\hline Pulmonary crepitations $\%$ & 19.1 & 28.9 & 0.004 \\
\hline \multicolumn{4}{|l|}{ Comorbidities } \\
\hline Hypertension \% & 72.2 & 73. & 0.653 \\
\hline Diabetes mellitus \% & 25.1 & 26.3 & 0.487 \\
\hline Chronic kidney disease \% & 8.4 & 5.3 & 0.432 \\
\hline Coronary artery disease $\%$ & 22.8 & 21.1 & 0.165 \\
\hline Cerebrovascular disease $\%$ & 6.1 & 5.2 & 0.365 \\
\hline Chronic obstructive pulmonary disease \% & 11.4 & 26.3 & 0.035 \\
\hline Atrial fibrillation \% & 26.7 & 47.3 & 0.001 \\
\hline \multicolumn{4}{|l|}{ Laboratory data } \\
\hline NT-proBNP, pg/ml & 321.8 & 612 & $<0.001$ \\
\hline Fasting blood glucose, $\mathrm{mg} / \mathrm{dl}$ & 99 & 98 & 0.165 \\
\hline Serum creatinine, $\mathrm{mg} / \mathrm{dl}$ & 0.82 & 0.81 & 0.378 \\
\hline Hemoglobin, g/dl & 12.2 & 12. 7 & 0.652 \\
\hline \multicolumn{4}{|l|}{ Echocardiography } \\
\hline LVEF, \% & 59 & 58 & 0.680 \\
\hline IVS dimension, $\mathrm{mm}$ & 12 & 11 & 0.451 \\
\hline$\geq$ Moderate mitral regurgitation & 65 & 10 & 0.040 \\
\hline Pulmonary systolic pressure $(\mathrm{mmHg})$ & 27 & 30 & 0.065 \\
\hline Systolic aortic regurgitation $\%$ & 7.6 & 26.3 & $<0.001$ \\
\hline
\end{tabular}

Data were presented as median or number (\%). NYHA: New York Heart Association; NT-proBNP: N-terminal pro B-type natriuretic peptide; LVEF: Left ventricle ejection fraction; IVS: Interventricular septum.

year was $12.6 \%$. Univariate analysis showed a significant association between age, presence of orthopnea and pulmonary crepitations, chronic obstructive pulmonary disease, atrial fibrillation, NT-proBNP, moderate or greater mitral regurgitation, and SAR with the primary outcome. On multivariate analysis, age (OR: $2.125 ; 95 \% \mathrm{CI}$ : 1.251-4.789; $\mathrm{p}=0.006)$, atrial fibrillation (OR: 1.954; 95\% CI: 1.190-4.621; $\mathrm{p}=0.005)$, NT-proBNP $>359$ $\mathrm{pg} / \mathrm{mL}$ (OR: 3.381; 95\% CI: 1.539-8.474; $\mathrm{p}<0.001$ ), and SAR (OR: 2.315; 95\% CI: $1.188-5.477 ; \mathrm{p}=0.008$ ) remained as significant variables associated with primary endpoints (Table 3).

\section{DISCUSSION}

The present study showed that all-cause mortality was
TABLE 3. Multivariate analysis for the prediction of the primary composite endpoint of all-cause death and hospitalization for heart failure in 12 months

\begin{tabular}{|c|c|c|c|}
\hline & OR & $95 \% \mathrm{Cl}$ & $\mathrm{p}$ \\
\hline Age (per 1 y) & 2.125 & $1.251-4.789$ & 0.006 \\
\hline $\begin{array}{l}\text { NT-proBNP }>359 \mathrm{pg} / \mathrm{mL} \\
\text { (median) }\end{array}$ & 3.381 & $1.539-8.474$ & $<0.001$ \\
\hline Orthopnea & 1.058 & $0.341-3.377$ & 0.912 \\
\hline $\begin{array}{l}\text { Atrial fibrillation } \\
\geq \text { Moderate mitral }\end{array}$ & 1.954 & $1.190-4.621$ & 0.005 \\
\hline regurgitation & 0.841 & $0.121-2.214$ & 0.254 \\
\hline Systolic aortic regurgitation & 2.315 & $1.188-5.477$ & 0.008 \\
\hline
\end{tabular}

OR: Odds ratio; NT-proBNP: N-terminal pro B-type natriuretic peptide; CI: Confidence interval. 
$3.9 \%$, HF-related hospitalization was $10.6 \%$ and, the incidence of death or hospitalization for HF was $12.6 \%$ in one year in ambulatory patients with HFpEF. To our knowledge, this is the first study showing an association between SAR and adverse events in patients with HFpEF. These results reveal the need for adding the assessment of SAR in the routine echocardiographic evaluation of the patients HF.

The HFPEF is currently the most common form of $\mathrm{HF}$, mainly because of the accelerated aging and high prevalence of comorbidities [14]. Identifying high and low-risk ambulatory patients with HFpEF can improve care by preventing delays in appropriate treatment for high-risk patients. However, currently available prediction models in patients with HF often contain variables that are not routinely collected in clinical practice [15] and data are limited in ambulatory HFpEF patients.

Previous studies revealed that aortic regurgitation is not always limited to diastole and, in certain hemodynamic situations, may also occur in systole [9-11]. Saura et al. [11] performed a prospective study of all echocardiographic examinations over one month. The SAR was detected in $2.3 \%$ of all investigations and it was detected in $5.9 \%$ of the patients with HF [11]. In another study, patients with dyspnea were included [16]. SAR was present in $3.3 \%$ of the patients, and the prevalence of HF was $40.3 \%$ [16]. The authors found that the specificity of SAR was $99.4 \%$ for the HF diagnosis [16]. Bonaque et al. [17] performed a prospective observational study and collected data from all outpatients referred to echocardiography. Of the 1042 patients, the prevalence of SAR was $1 \%$ and the prevalence of HF was $12 \% .46 \%$ of the patients with HF had HFpEF in this single-center study [17]. The authors found that all patients with SAR had HF, and in the subpopulation of patients with HF, SAR was found in 9\%. During follow-up, nine of the 11 patients with SAR were admitted to hospital for HF and, four out of 11 patients with SAR died of HF [17]. Although our study had some methodological differences with this study, we found a similar SAR prevalence of $9.9 \%$ in our study group of patients with HFpEF. Our result also revealed that the presence of SAR was an independent predictor of outcomes in outpatients with HFpEF. The incidence of primary composite endpoint in one year was higher for patients with SAR (26.3\%) compared to the patients without SAR (7.6\%). Our preliminary study, to our knowledge, is the first to demonstrate an impact of SAR on the outcome of HFpEF. However, it is premature to recommend SAR as a predictor of adverse events in all HF patients and the incremental value of SAR for prediction of complications should be investigated in further prospective clinical trials.

\section{Study Limitations}

This is a single centre study, including only ambulatory patients with HFpEF. Patients who had HF with reduced-or mid-range left ventricular ejection fraction, and patients who were hospitalized for HF were excluded in this study.

\section{Conclusion}

To our knowledge, this study provides the first evidence about the prevalence and significance of SAR in an unselected outpatient population of HFpEF. Our study revealed that, although it was not common, the presence of SAR portends a poor prognosis in patients with HFpEF.

Ethics Committee Approval: The Mugla Sitki Kocman University Clinical Research Ethics Committee granted approval for this study (date: 16/08/2016, number: 14/II).

Conflict of Interest: No conflict of interest was declared by the authors.

Financial Disclosure: The authors declared that this study has received no financial support.

Authorship Contributions: Concept - IB; Design - MB; Supervision - IB; Fundings - MB; Materials - IB; Data collection and/ or processing - MB; Analysis and/or interpretation - MB; Literature review - IB; Writing - IB; Critical review - MB.

\section{REFERENCES}

1. Oren O, Goldberg S. Heart Failure with Preserved Ejection Fraction: Diagnosis and Management. Am J Med 2017;130:510-6. [CrossRef]

2. Özlek B, Özlek E, Ağuş HZ, Tekinalp M, Kahraman S, Çil C, et al. Patients with HFpEF and HFmrEF have different clinical characteristics in Turkey: A multicenter observational study. Eur J Intern Med 2019;61:88-95. [CrossRef]

3. Yee D, Novak E, Platts A, Nassif ME, LaRue SJ, Vader JM. Comparison of the Kansas City Cardiomyopathy Questionnaire and Minnesota Living With Heart Failure Questionnaire in Predicting Heart Failure Outcomes. Am J Cardiol 2019;123:807-12. [CrossRef]

4. Hashimoto H, Nakanishi R, Mizumura S, Hashimoto Y, Okamura Y, Kiuchi S, et al. Prognostic Value of 123I-BMIPP SPECT in Patients with Nonischemic Heart Failure with Preserved Ejection Fraction. J Nucl Med 2018;59:259-65. [CrossRef]

5. Nikolova AP, Hitzeman TC, Baum R, Caldaruse AM, Agvanian S, Xie Y, et al. Association of a Novel Diagnostic Biomarker, the Plasma Cardiac Bridging Integrator 1 Score, With Heart Failure With Preserved Ejection Fraction and Cardiovascular Hospitalization. JAMA Cardiol 2018;3:1206-10. [CrossRef] 
6. Ohtani T, Mohammed SF, Yamamoto K, Dunlay SM, Weston SA, Sakata Y, et al. Diastolic stiffness as assessed by diastolic wall strain is associated with adverse remodelling and poor outcomes in heart failure with preserved ejection fraction. Eur Heart J 2012;33:1742-9. [CrossRef]

7. Lam CS, Roger VL, Rodeheffer RJ, Borlaug BA, Enders FT, Redfield MM. Pulmonary hypertension in heart failure with preserved ejection fraction: a community-based study. J Am Coll Cardiol 2009;53:111926. [CrossRef]

8. Burke MA, Katz DH, Beussink L, Selvaraj S, Gupta DK, Fox J, et al. Prognostic importance of pathophysiologic markers in patients with heart failure and preserved ejection fraction. Circ Heart Fail 2014;7:288-99. [CrossRef]

9. Duyuler S, Türker Duyuler P. Accentuating systolic aortic regurgitation during premature ventricular systole. Anatol J Cardiol 2017;18:E3-4.

10. Mohan JC, Mohan V, Shukla M, Sethi A. Systolic aortic regurgitation in rheumatic carditis: Mechanistic insight by Doppler echocardiography. Indian Heart J 2018;70:272-7. [CrossRef]

11. Saura D, Peñafiel P, Martínez J, de la Morena G, García-Alberola A, Soria $\mathrm{F}$, et al. The frequency of systolic aortic regurgitation and its relationship to heart failure in a consecutive series of patients. [Article in Spanish]. Rev Esp Cardiol 2008;61:771-4. [CrossRef]

12. Ponikowski P, Voors AA, Anker SD, Bueno H, Cleland JGF, Coats AJS, et al; ESC Scientific Document Group. 2016 ESC Guidelines for the diagnosis and treatment of acute and chronic heart failure: The Task Force for the diagnosis and treatment of acute and chronic heart failure of the European Society of Cardiology (ESC)Developed with the special contribution of the Heart Failure Association (HFA) of the ESC. Eur Heart J 2016;37:2129-200. [CrossRef]

13. Rudski LG, Lai WW, Afilalo J, Hua L, Handschumacher MD, Chandrasekaran K, et al. Guidelines for the echocardiographic assessment of the right heart in adults: a report from the American Society of Echocardiography endorsed by the European Association of Echocardiography, a registered branch of the European Society of Cardiology, and the Canadian Society of Echocardiography. J Am Soc Echocardiogr 2010;23:685-713. [CrossRef]

14. Özlek B, Özlek E, Tekinalp M, Kahraman S, Ağuş HZ, Çelik O, et al. Clinical features of heart failure with mid-range and preserved ejection fraction in octogenarians: Results of a multicentre, observational study. Int J Clin Pract 2019;73:e13341. [CrossRef]

15. Voors AA, Ouwerkerk W, Zannad F, van Veldhuisen DJ, Samani NJ, Ponikowski P, et al. Development and validation of multivariable models to predict mortality and hospitalization in patients with heart failure. Eur J Heart Fail 2017;19:627-34. [CrossRef]

16. Saura D, López-Cuenca A, Oliva MJ, Caballero L, González-Carrillo J, Espinosa MD, et al. Accuracy of systolic aortic regurgitation in the diagnosis of heart failure: a predictive approach. Int J Clin Pract 2015;69:485-90. [CrossRef]

17. Bonaque JC, Sánchez-Espino AD, Merchán G, González-Juanatey JR. Systolic aortic regurgitation. A new prognostic marker in heart failure patients?. Rev Esp Cardiol (Engl Ed) 2015;68:160-2. [CrossRef] 